\title{
The Effect of Combined Tensile-Torsional Loading Path on the Stress/Strain States of Thin-Walled Circular Tubes
}

\author{
Yue Gao $\mathbb{D}^{D}$, Fei Shao $(\mathbb{D}$, Qian Xu $(\mathbb{D}$, Linyue Bai $(\mathbb{D})$, Qingna Ma $(\mathbb{D}$, Mei Shen $(\mathbb{D}$, Lixiang He, \\ and Ming Chen
}

Field Engineering College, Army Engineering University of PLA, Nanjing 210007, China

Correspondence should be addressed to Fei Shao; shaofei@seu.edu.cn and Qian Xu; 1058427910@qq.com

Received 12 October 2020; Revised 13 November 2020; Accepted 23 November 2020; Published 29 December 2020

Academic Editor: Giovanni Minafò

Copyright (c) 2020 Yue Gao et al. This is an open access article distributed under the Creative Commons Attribution License, which permits unrestricted use, distribution, and reproduction in any medium, provided the original work is properly cited.

\begin{abstract}
In this paper, an elastoplastic analysis model of thin-walled circular tubes under the combined action of axial force and torque is discussed. Based on the von Mises yield criterion and the assumption of isotropic linear hardening, the methods of stress path and strain path loading are analyzed to study the effect of combined tensile-torsional loading path on thin-walled circular tubes. A finite element model is used to analyze the loading path effect on thin-walled circular tubes. A series of tensile and torsional tests are also carried out on 304 stainless steel thin-walled circular tubes using a universal testing machine. In addition, the consistency of the selected material with the von Mises yield criterion, the assumption of isotropic linear hardening, and other classical elastoplastic mechanics are verified. The theoretical calculation results, the numerical analysis results, and the experimental test results are analyzed and compared. The "primary effect" influenced by the stress path and the "recency effect" affected by the strain path are proved, and their application prospects are discussed. The influence of tensile-torsional loading path on the final stress and strain states of thin-walled circular tubes after entering the plastic deformation stage is concretely demonstrated, facilitating the understanding of the principles of the aforementioned two effects. The investigation for a general principle concerning the effect of loading history on the mechanical behavior of engineering materials, based on the classical plastic mechanics, has an important theoretical significance. It is of great theoretical importance for advancements in plastic yield theory and the establishment of more accurate loading conditions suitable for specific materials in engineering practice.
\end{abstract}

\section{Introduction}

Thin-walled circular tube is a basic space structure, which has a wide range of applications and research interest. So far, a variety of studies have been conducted on the mechanical behavior of metallic tubes in the plastic regime. The theory and testing techniques for the stress and strain of a thinwalled circular tube under pure axial tension or torsion are mature, while the experimental research on the corresponding mechanical properties of the thin-walled circular tube showed great differences due to the complexity of the loading combined deformation. Shu et al. [1] studied the mutual interaction law of tensile stress-strain and torsional stress-strain on a V150 drill (Supplementary Materials (Available here)) tube under combined tensile-torsional loading conditions. It was found that designing the tensile- torsional loading capacity of the V150 drill tube based on the von Mises strength criterion was conservative, while designing it on the basis of the tensile-torsional elliptical strength criterion could give full play to the mechanical properties of drill tubes. Aida et al. [2] investigated the combined resonance of thin-walled members subjected to periodic torque and force. Wang et al. [3] carried out tensiletorsional fatigue tests and finite element theoretical calculations on No. 45 steel thin-walled circular tube specimens containing holes, analyzed their fatigue characteristics, and predicted service life. Chaves et al. [4] carried out tensile, torsional, and tensile-torsional tests on 304 stainless steel thin-walled circular tube specimens with perforations and investigated fatigue limit and crack propagation direction. They found that crack initiation points were all located near the maximum stress point of surface around the hole. 
Bodaghi et al. [5] proposed a macroscopic phenomenological model for shape memory alloys. They showed that the results obtained for uniaxial tensile and biaxial combined tensile-torsional nonproportional tests using the proposed model were in good agreement with corresponding experiments. Hu et al. [6] combined the tensile-torsional experiments of pretension and pretorsion deformations and studied the grain-scale yield characteristics of polycrystalline $\mathrm{Cu}$ and the influences of different loading paths and yield point definitions on the subsequent material yield surface. Zhang et al. [7] developed a new image-based single-camera tensile-torsional strain measurement method. The results obtained by this method were compared with those of DIC (digital image correlation) through experiments, which proved the reliability of this method.

As for the problem of combined tensile-torsional loads on thin-walled circular tubes, the existing literature mainly investigated the mechanical behavior $[1,2,8-12]$, fatigue and cracks $[3,4,13-15]$, shape memory alloys $[5,16]$, microstructure $[6,17]$, loading path control $[18]$, strain measurement method [7], composite phase change wave [19], buckling analysis [20], and other aspects of engineering materials by numerical methods and experimental tests. However, most related research studies are individualized cases for specific materials, and only a few studies focus on the influence of different loading paths on the mechanical behavior of engineering materials in general.

Chen et al. [21] developed analytical solutions for plastic strain under three stress paths (tension followed by torsion, proportional loading, and torsion followed by tension) when the stress endpoint was $\left(\sigma_{s}, \sigma_{s} / \sqrt{3}\right)$. Xu et al. [22] derived analytical solutions for stress results under three strain paths (tension followed by torsion, proportional loading, and torsion followed by tension) when the strain endpoint was $\left(\sigma_{s} / E, t \sigma_{s} / \sqrt{3} G\right)$. These two classical cases illustrated that stress paths greatly affected plastic strain and strain paths played an important role in the resultant stress results; however, the influence rule of loading history was not established.

Through rigorous mathematical derivation, Gao et al. derived the "primary effect" (i.e., for the same stress endpoint, the strain results satisfied: $\varepsilon_{z}^{A}>\varepsilon_{z}^{B}>\varepsilon_{z}^{C}, \gamma_{\theta z}^{A}<\gamma_{\theta z}^{B}<\gamma_{\theta z}^{C}$ under different stress paths) affected by the stress path and "recency effect" (i.e., for the same strain endpoint, the stress results satisfied: $\sigma_{z}^{A}<\sigma_{z}^{B}<\sigma_{z}^{C}, \tau_{\theta z}^{A}>\tau_{\theta z}^{B}>\tau_{\theta z}^{C}$ under different strain paths) influenced by strain path, and pointed out the relevance and unity of the "primary effect" and "recency effect" [23]. However, the laws of "primary effect" and "recency effect" of the loading path are only based on theoretical derivations and proofs and their validity in actual engineering materials needs to be verified. Therefore, it is necessary to obtain strain/stress results under different stress/strain loading paths by the finite element method and experiments, providing numerical and experimental basis for "primary effect" and "recency effect".

The thin-walled circular tube analysis model presented in this article (as shown in Figure 1) is not for a specific material, not for a certain size of tube, but represents the generalized thin-walled tube analysis model. It is verified

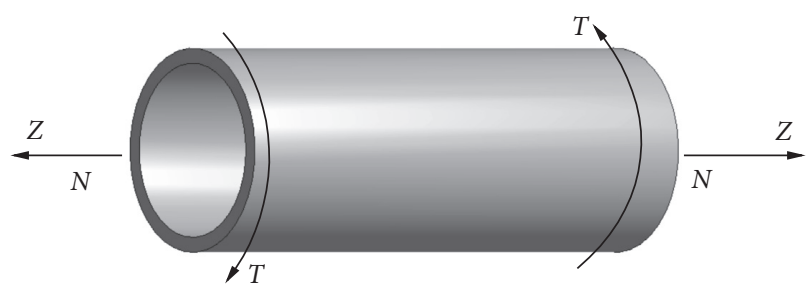

FIGURE 1: Thin-walled circular tube analysis model (From reference [23]).

that the developed thin-walled circular tube model is consistent with the von Mises yield criterion, the assumption of isotropic linear hardening, and other classical elastoplastic mechanics theories through a series of tensile and torsional tests. Based on this model, the influence of the loading path on the final stress/strain state of the thin-walled circular tube model is analyzed. The loading method for the loading path of thin-walled circular tubes is also analyzed. The results of stress path tensile-torsional loading tests on 304 stainless steel thin-walled tubes and finite element analyses are given. The results obtained from theoretical calculations, finite element analyses, and experimental tests are compared and analyzed to verify that the loading path is affected by the "primary effect" and "recency effect". The thin-walled tube analysis model in classical plastic mechanics is closely linked with the well-known "primary effect" and "recency effect" in social psychology, and it has played a very good role in the teaching practice of "elastoplastic mechanics". This attempt to simplify complex issues can help students quickly judge the correctness of the results of the problems on the stress/ strain path and deepen the understanding of the impact of the loading path on plastic deformation. In addition, it has practical significance for establishing more accurate loading conditions suitable for specific materials in engineering practice and presents good application prospects. The conclusions drawn in this paper have strong universality, which has a good promotion effect on the development of plastic mechanics.

\section{Materials and Methods}

Regarding the theoretical analysis model presented in the literature [23], an analysis model of a thin-walled circular tube subjected to axial ( $Z$-axis refers to the direction along tube's axis) tension and torque was established, which conformed to the von Mises yield criterion and the assumption of isotropic linear hardening.

2.1. Sample Preparation. 304 stainless steel (0Cr18Ni9) thinwalled circular tubes were chosen as specimens with actual sizes of $D_{0}=29.9 \mathrm{~mm}, d_{0}=25.4 \mathrm{~mm}$, and $S_{0}=195.4 \mathrm{~mm}^{2}$.

According to ISO6892-1 Metallic materials-Tensile testing [24], the original gauge length of the specimen was determined as follows:

$$
\begin{aligned}
L_{0} & =5.65 \sqrt{S_{0}}=79.0 \mathrm{~mm}, \\
\text { Chosen } L_{0} & =80 \mathrm{~mm} .
\end{aligned}
$$


Then, the parallel length of the circular tube specimen was determined as follows:

$$
\begin{aligned}
L_{c} \geq L_{0}+\left(\frac{D_{0}}{2}\right) & =95 \mathrm{~mm}, \\
\text { chosen } L_{c} & =95 \mathrm{~mm} .
\end{aligned}
$$

The clamping length $\left(L_{h}\right)$ was determined to be $60 \mathrm{~mm}$, according to the size of the fixture in the testing machine.

The total length $\left(L_{t}\right)$ of the specimen was determined by $L_{c}$ and $L_{h}$ using the following equation:

$$
L_{t}=L_{c}+2 L_{h}=215 \mathrm{~mm} .
$$

Q235 circular steel was adopted as the plug with a measured diameter of $25 \mathrm{~mm}$. The length of the plug $L_{b}$ was determined as follows:

$$
\begin{aligned}
L_{b}=L_{h}+\left(\frac{D_{0}}{4}\right) & =67.5 \mathrm{~mm}, \\
\text { chosen } L_{b} & =68 \mathrm{~mm} .
\end{aligned}
$$

In order to avoid the residual stresses caused by welding, the metal adhesive was used to bond the circular tube with the plug.

The standard specimen of 304 stainless steel thin-wall circular tube, made according to the above size requirements, is shown in Figure 2.

2.2. Classical Theory Conformity Verification. The analytic model of thin-walled circular tubes subjected to axial tension and torque in the literature [23] conforms to the von Mises yield criterion and assumptions of isotropic linear hardening and other classical elastoplastic mechanics. To verify the consistency of the selected 304 stainless steel thin-walled circular tubes with the classical theory, a Sansi UTM5305 universal testing machine (Shenzhen Suns Test Equipment Co. Ltd., Shenzhen, Guangdong, China) was used to perform two sets of confirmatory tests on the standard specimens, namely "tensile" and "load-unload-load" tests, as shown in Figure 3. The nominal tensile stress-strain curve of the standard specimen was obtained according to the tensile test of the specimen, and the modified stress-strain curve is obtained according to the principle of constant volume and uniform deformation, as shown in Figure 4(a). In addition, the stress-strain curve of the whole process was also obtained according to the "load-unloadload" test, as shown in Figure 4(b). The MTS809 tensile-torsional testing system (MTS Systems Inc, Eden Prairie, Minnesota, USA), as shown in Figure 5, was used to conduct torsion tests on the standard specimen, and the shear stressrotation curves were obtained, as shown in Figure 6.

It can be seen from Figures 4(a) and 6 that the tensile and torsional stress/strain curves of 304 stainless steel thin-walled circular tubes are linear in the elastic stage. Linear characteristics are also obvious in the strengthening stage, which is in accordance with the classical "bilinear isotropic hardening" theory. From Figures 4(b) and 6, it can be seen that the three elastic straight sections (first loading elastic section, unloading elastic section, and second loading elastic section) are essentially parallel indicating that plastic deformation does not affect the intrinsic elastic modulus of the material. The elastic deformation part of the second loading becomes longer and the subsequent yielding starts from the unloading point, indicating that yield strength is improved. This indicates that 304 stainless steel thin-walled circular tubes are consistent with the theories of classical elastoplastic mechanics, which can be used to reasonably analyze the loading path effect of thin-walled tubes.

\subsection{Measurement and Calibration of Mechanical Parameters.} Based on the tensile and torsional tests of standard specimens, the elastic modulus and yield stress of the material were obtained as follows:

$$
\begin{aligned}
E & =210 \mathrm{GPa}, \\
\sigma_{s} & =353 \mathrm{MPa}, \\
\tau_{s} & =204 \mathrm{MPa} .
\end{aligned}
$$

Ultimate strength $\sigma_{u}$ was calculated to be $1073 \mathrm{MPa}$ based on the principle of constant volume and uniform deformation. However, the necking deformation of the specimen was uneven during the stretching process. The necking phenomenon was smaller near the clamping end and larger near the middle, as shown in Figure 7(a). In addition, the cross-sectional area of the specimen was measured at different locations after testing, showing a linear reduction trend moving from edge towards center, as shown in Figure 7(b). The cross-sectional area at the fracture was calculated to be $112.2 \mathrm{~mm}^{2}$ (the lower limit of the $95 \%$ confidence interval was $105.0 \mathrm{~mm}^{2}$, and the upper limit of the $95 \%$ confidence interval was $119.4 \mathrm{~mm}^{2}$ ) through linear fitting. Combined with the maximum tensile force of $127 \mathrm{kN}$ obtained by the testing machine, the true ultimate strength $\left(\sigma_{u}\right)$ was calculated to be $1134 \mathrm{MPa}$ (the lower limit of the $95 \%$ confidence interval was $1066 \mathrm{MPa}$, and the upper limit of the $95 \%$ confidence interval was $1212 \mathrm{MPa}$ ).

Due to the limited range of extension measurement, the second inflection point in Figure 4(a) corresponds to extensometer removal. The part of the strengthening stage before the second inflection point truly reflects the plastic modulus $(h)$ of the material in the strengthening stage, which was determined to be $1.77 \mathrm{GPa}$.

The aforementioned mechanical parameters provided basic data for the subsequent tensile-torsional tests and finite element analysis using ANSYS.

\subsection{Loading Paths}

2.4.1. Stress Paths. Chen et al. [21] gave the analytical solution of plastic strain under three stress paths (as shown in Figure $8(\mathrm{a})$ ) when the stress end point is $\left(\sigma_{s}, \sigma_{s} / \sqrt{3}\right)$. Gao et al. [23] proved that the "primary effect" is not only valid for $\left(\sigma_{s}, \sigma_{s} / \sqrt{3}\right)$ but for the entire stress space outside the initial yield surface (including areas I, II, III, and IV). Through experiments and numerical methods, this paper proves the universality of "primary effect" in the entire plastic stress space. The three loading paths to $\left(\sigma_{s}, \sigma_{s} / \sqrt{3}\right)$ are as follows: 


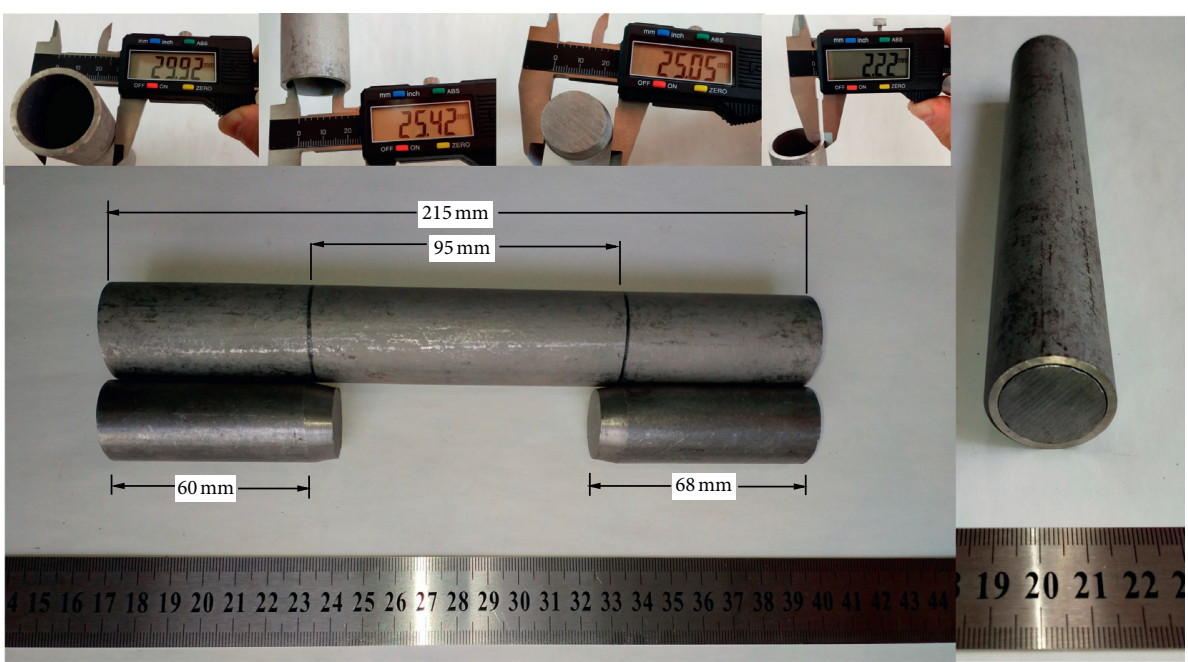

FIGURE 2: Standard specimen size and structure of a 304 stainless steel thin-wall circular tube.

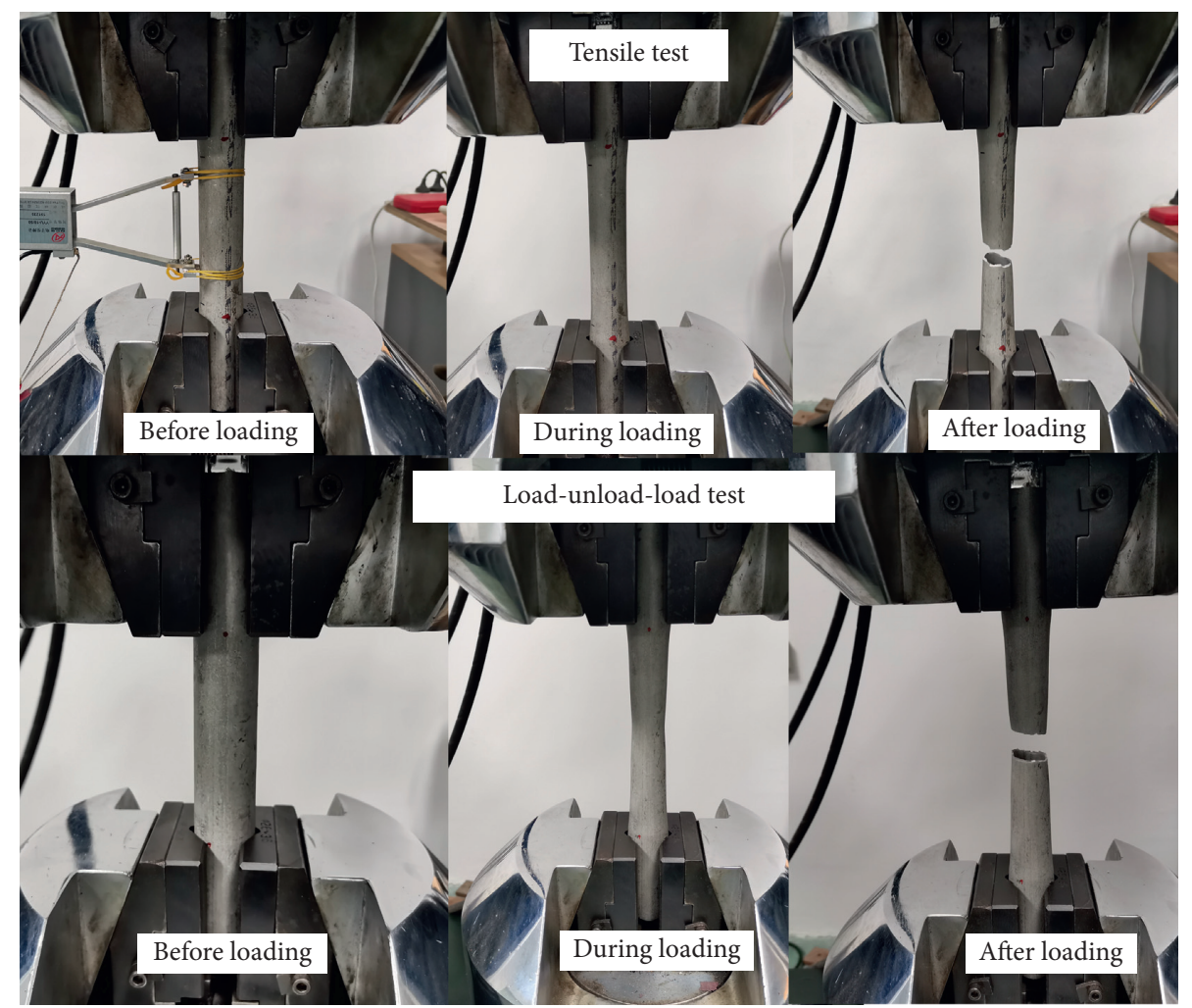

Figure 3: "Tensile" and "load-unload-load" tests.

(1) Stress path A : first, normal stress is increased along axial direction to $\sigma_{z}=\sigma_{s}$. Then, it is kept constant, while the shear stress is increased to $\tau_{\theta z}=\sigma_{s} / \sqrt{3}$.

(2) Stress path B: stress is increased to $\sigma_{z}=\sigma_{s}$ and $\tau_{\theta z}=$ $\sigma_{s} / \sqrt{3}$ with a proportion of $\sigma_{z}: \tau_{\theta_{z}}=1: 1 / \sqrt{3}$.

(3) Stress path $C$ : first, shear stress is increased to $\tau_{\theta z}=\sigma_{s} / \sqrt{3}$. Then, it is kept constant, while normal stress is increased to $\sigma_{z}=\sigma_{s}$.
2.4.2. Strain Paths. Xu et al. [22] gave the analytical solution of stress under three strain paths (as shown in Figure 8(b)) when the strain end point is $\left(\sigma_{s} / E, t \sigma_{s} / \sqrt{3} G\right)$. Gao et al. [23] proved that the "recency effect" is not only valid for $\left(\sigma_{s} / E, t \sigma_{s} / \sqrt{3} G\right)$ but for the entire strain space outside the initial yield surface (including areas I, II, III, and IV). Through numerical methods, this paper proves the universality of "recency effect" in the entire plastic strain space. The three loading paths to $\left(\sigma_{s} / E, t \sigma_{s} / \sqrt{3} G\right)$ are as follows: 


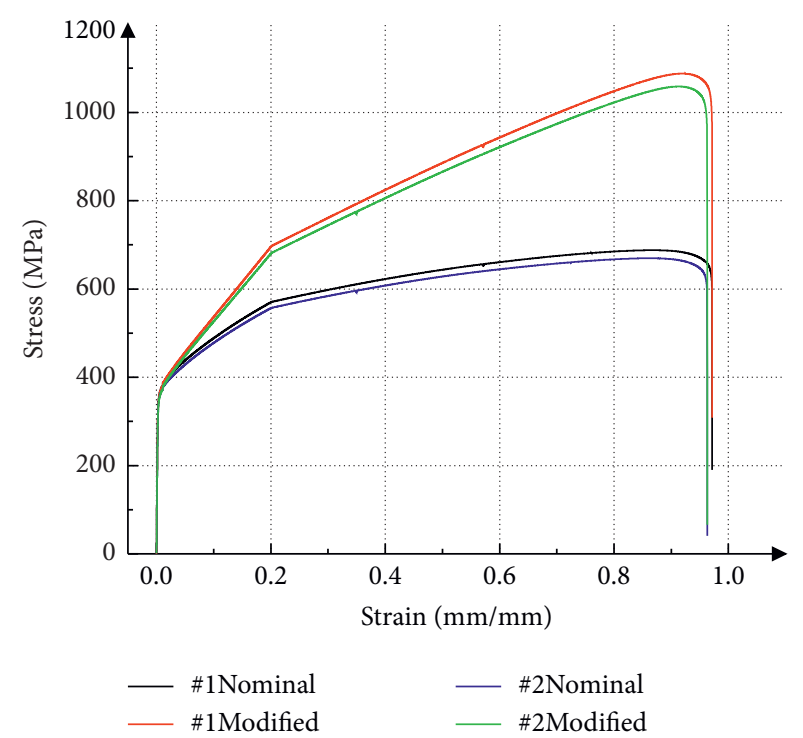

(a)

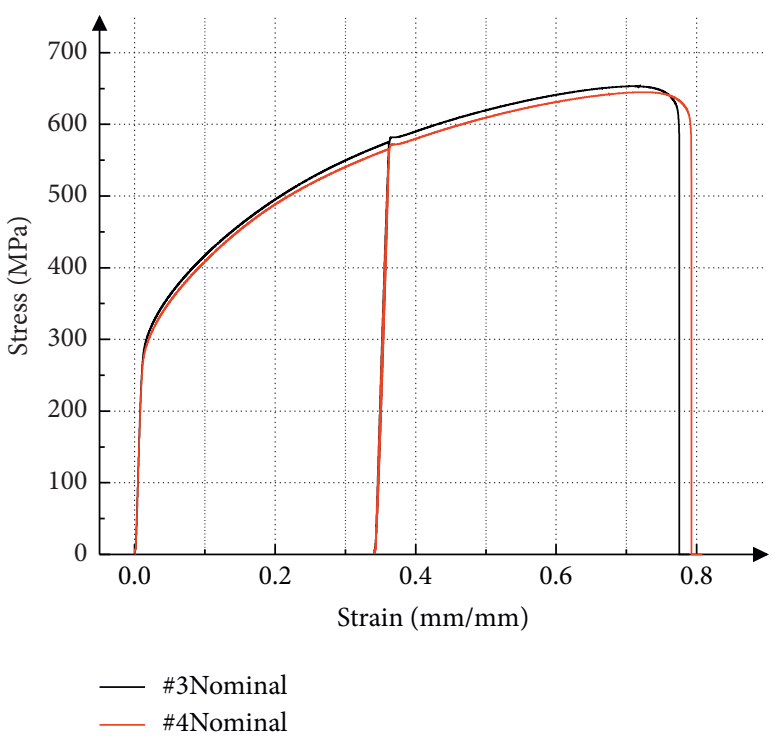

(b)

Figure 4: Tensile stress-strain curves.

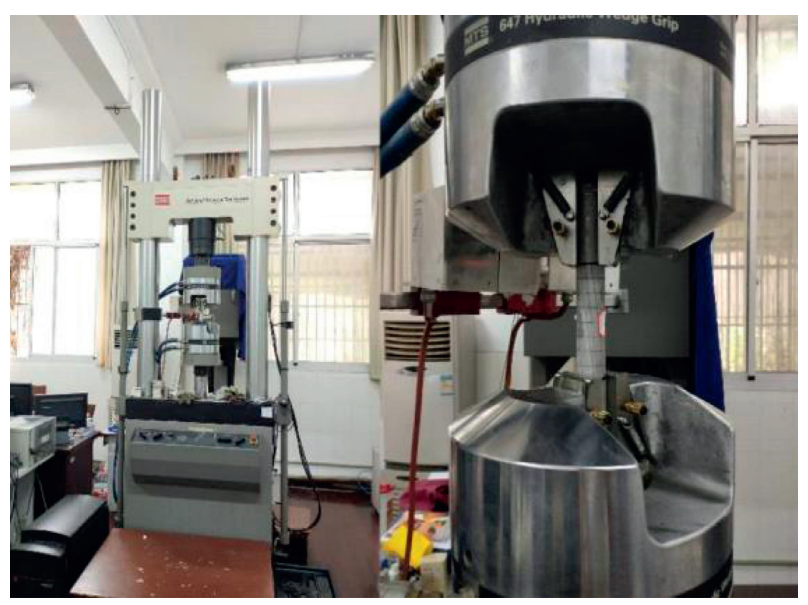

FIGURE 5: Torsion test performed on a standard specimen.

(1) Strain path A : first, normal strain is increased along axial direction to $\varepsilon_{z}=\sigma_{s} / E$. Then, it is kept constant, while shear strain is increased to $\gamma_{\theta_{z}}=\sigma_{s} / \sqrt{3} G$.

(2) Strain path B: strain is increased to $\varepsilon_{z}=\sigma_{s} / E$ and $\gamma_{\theta z}=\sigma_{s} / \sqrt{3} G$ with a proportion of $\varepsilon_{z}: \gamma_{\theta_{z}}=1: 2(1+\mu) / \sqrt{3}$.

(3) Strain path $C$ : first, shear strain is increased to $\gamma_{\theta z}=\sigma_{s} / \sqrt{3} G$. Then, it is kept constant while normal strain is increased to $\varepsilon_{z}=\sigma_{s} / E$.

\section{Results and Analysis}

ANSYS 19.2 Workbench was used for finite element analysis (FEA) of the model under different loading paths. The MTS809 tensile-torsional combined material testing system was used to measure the strain results of the standard specimens under different stress loading paths. Ultimately,
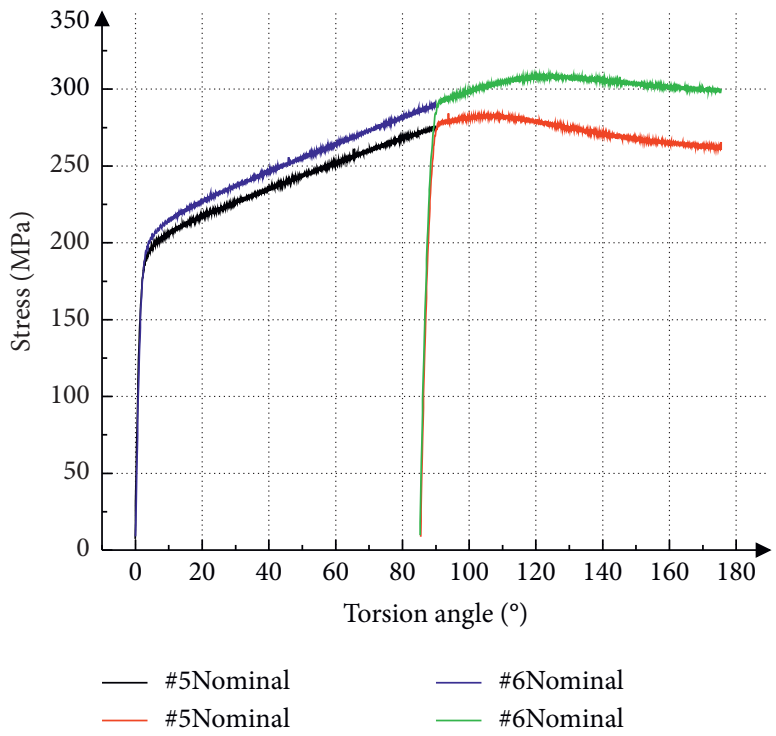

FIGURE 6: Shear stress-rotation curves.

the theoretical, FEA, and experimental test results were compared and analyzed.

\subsection{Results of FEA}

3.1.1. FEA Model Setup. The mechanical parameters of stainless steel in the material database were modified as follows:

$$
\begin{aligned}
E & =210 \mathrm{GPa}, \\
\sigma_{s} & =353 \mathrm{MPa}, \\
h & =1.77 \mathrm{GPa}, \\
\mu & =0.4999 .
\end{aligned}
$$




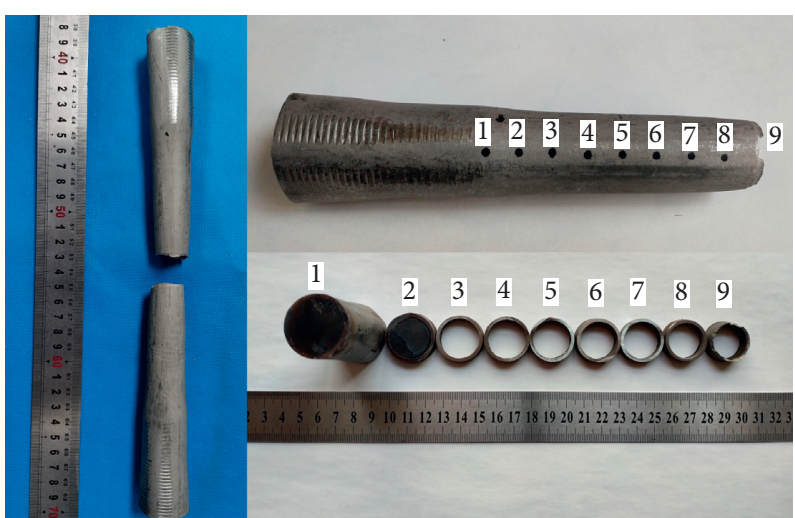

(a)

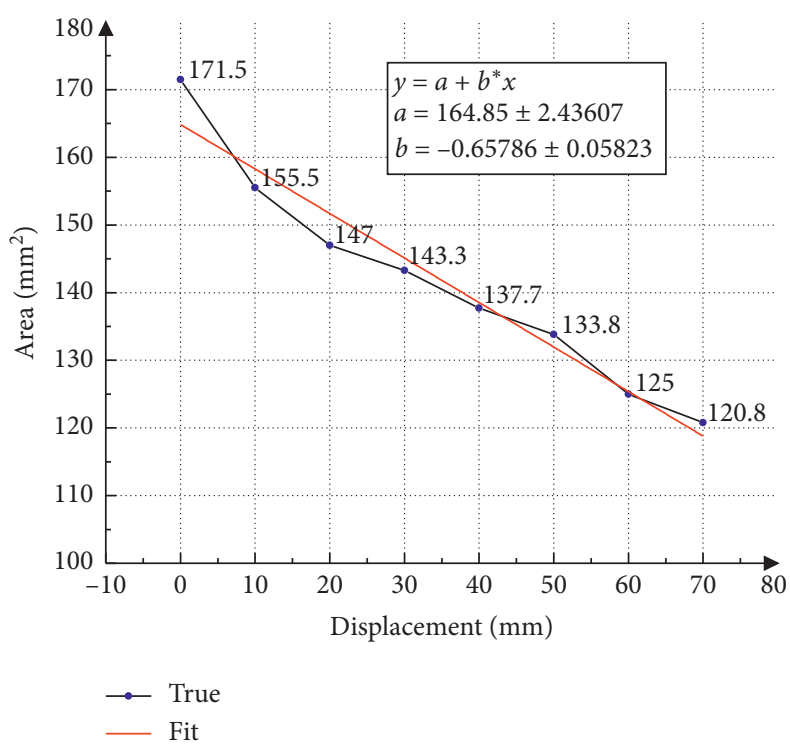

(b)

Figure 7: The morphology (a) and change curves (b) for the cross-sectional area of the standard specimen after the fracture. Note. R-square of the fitted straight line is 0.94761 .

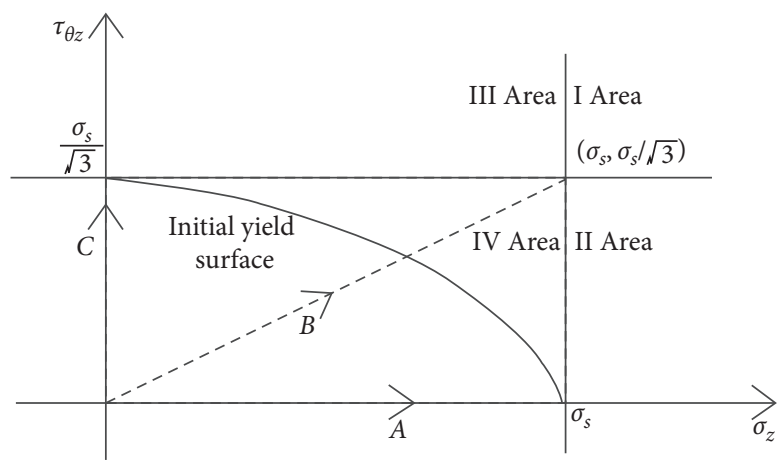

(a)

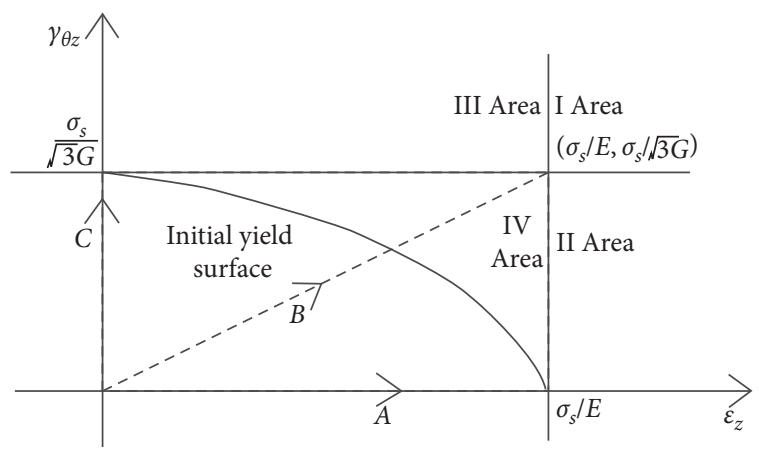

(b)

Figure 8: Stress (a) and strain (b) path loading diagram.

The stress-strain curve conforms to the bilinear isotropic hardening model using these parameters. Shell elements were used to build the model geometry based on the dimensions of the 304 stainless steel thin-walled circular tube standard specimen. Slicing was performed to divide the circular tube at the middle section, and an operation of Form new part was performed to the two sections of the circular tube. A cylindrical coordinate system, based on the global coordinate system, was established for analysis. The specimen was meshed using a uniform element size of $2.5 \mathrm{~mm}$ (see Figure 9 for mesh sensitivity analysis). The elements in the middle section were selected for detailed analysis and labeled as "Selection 1," as shown in Figure 10(c). With reference to the cylindrical coordinate system, one end on the specimen was constrained in $Y$ and $Z$ directions, while the other end was subjected to loading in terms of either force or displacement, for stress path loading or strain path loading, respectively (see Figures 11 and 12).
Furthermore, following parameters were modified for the solver, while default settings were used for the rest:

Number of steps $=8$

Step end time settings are shown in Figures 11 and 12

Auto time stepping $=$ Off

Define by $=$ Substeps

Number of substeps $=10$

Solver type $=$ Direct

Large deflection $=$ On

Next, the stress and strain values of the labeled elements (Selection 1) were calculated according to the Saint-Venant principle. The strain results of the stress path loading are shown in Table 1, while the stress results of the strain path loading are shown in Table 2. The analysis process and 


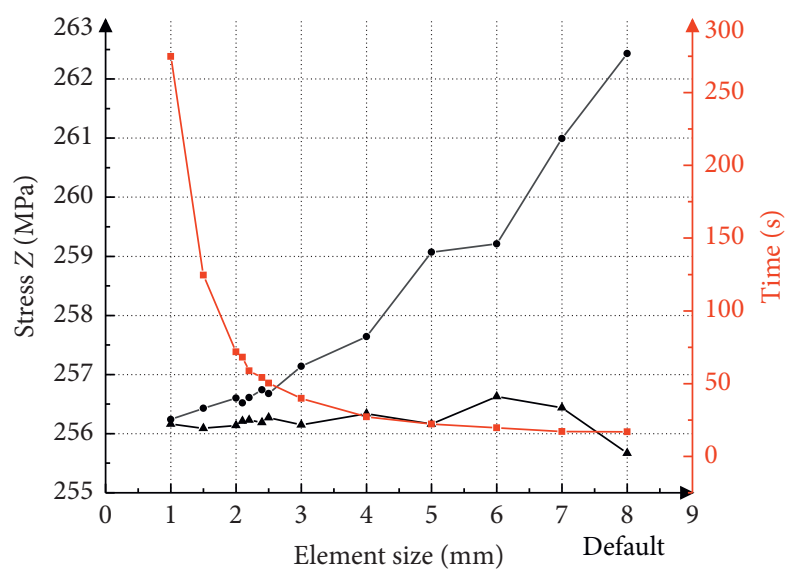

- Stress $Z$ max

- Stress $Z$ min

$\rightarrow$ Time

FIgURe 9: Mesh sensitivity analysis diagram.

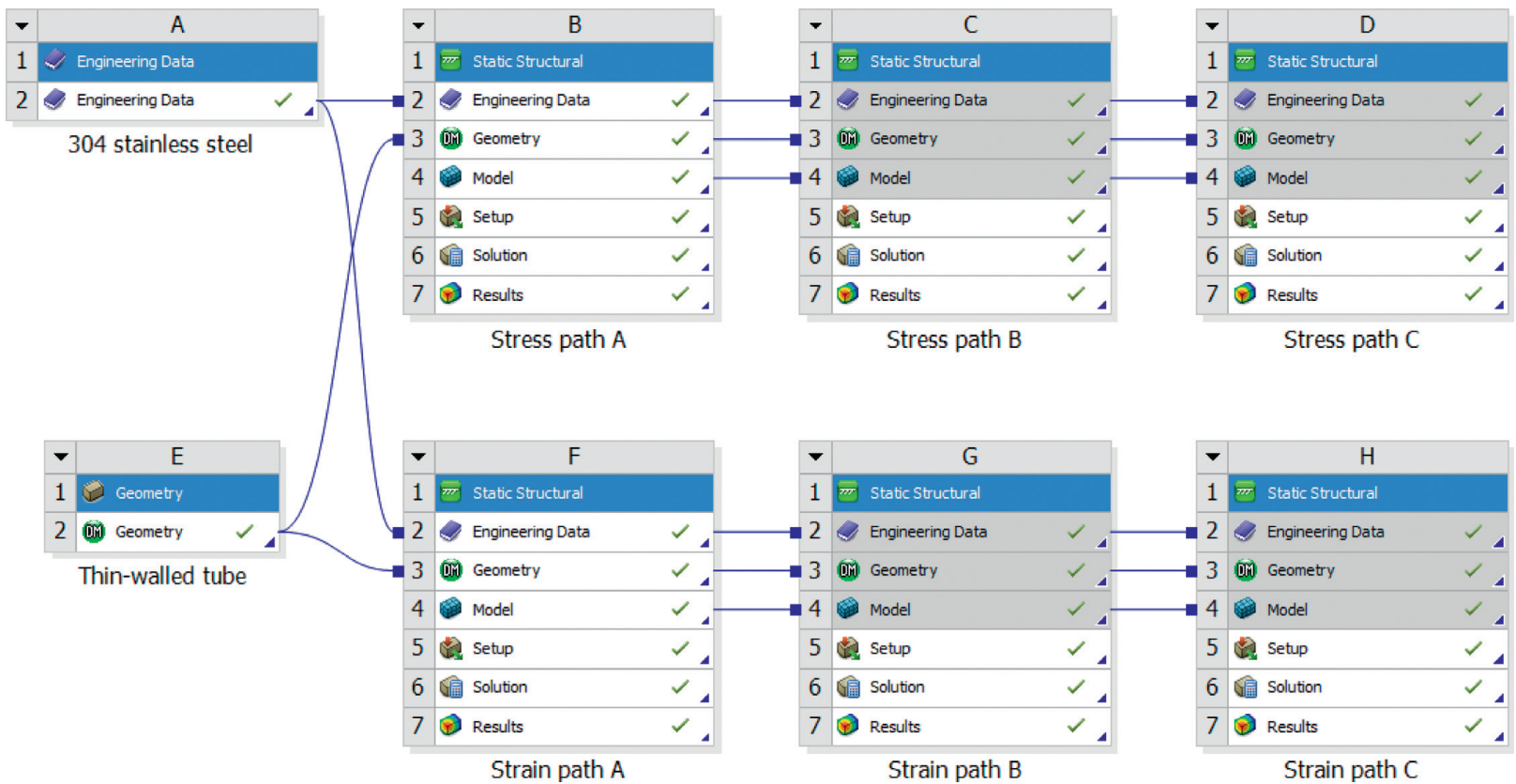

(a)

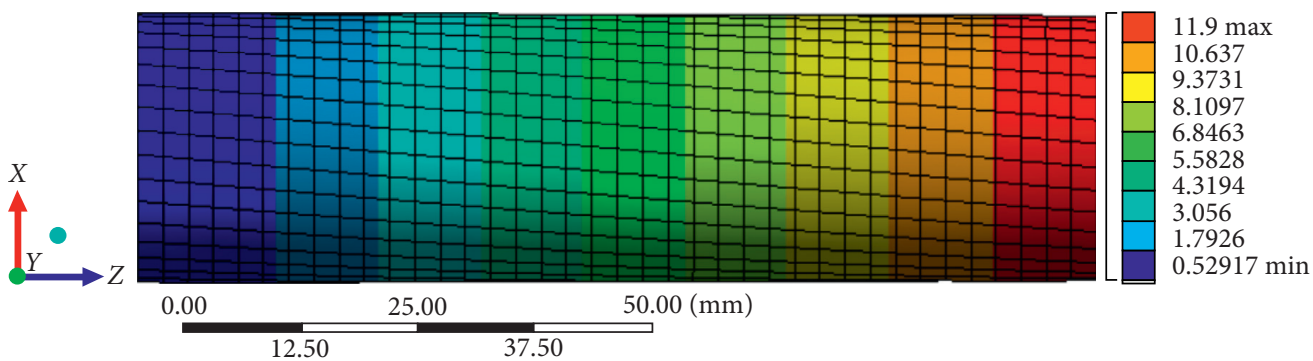

(b)

Figure 10: Continued. 


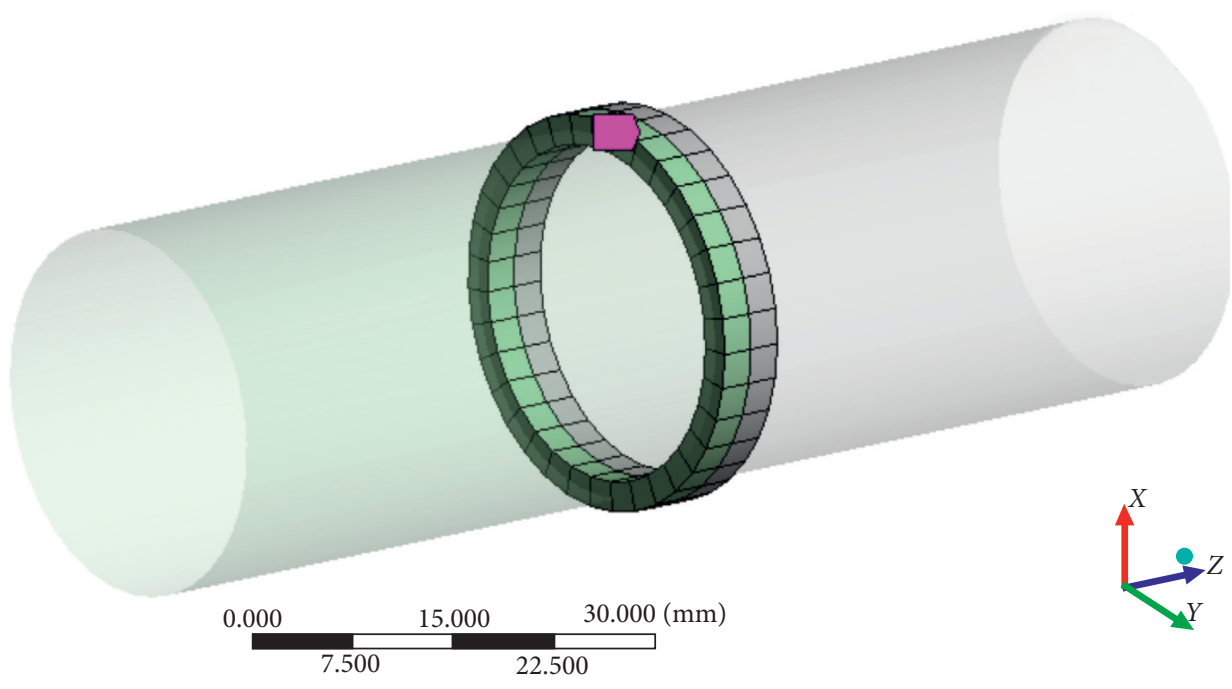

Selection 1

(c)

Figure 10: FEA process (a), rendering effect diagram of tension and torsion (b), and the elements of Selection 1 (c).

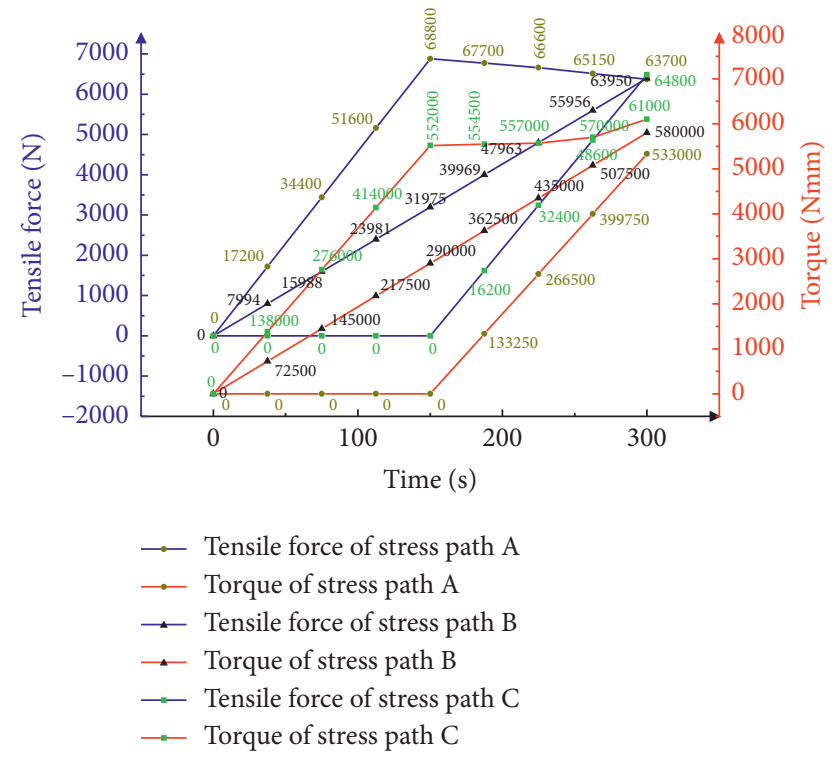

Figure 11: Three different stress path loading schemes.

rendering effect diagrams of tension and torsion are shown in Figures 10(a) and 10(b), respectively.

3.1.2. Mesh Sensitivity Analysis. For mesh sensitivity analysis, a calculation case was setup for the model. Same dimensions, geometry, boundary conditions, and computer were used for each iteration of this process to ensure consistency and reliability. The calculation result considers the maximum and minimum stress values of the selected elements on the middle section of the specimen. The stress calculation results and the calculation time taken by the computer are shown in Figure 9. The results were considered converged at a mesh size of $2.5 \mathrm{~mm}$ meeting accuracy

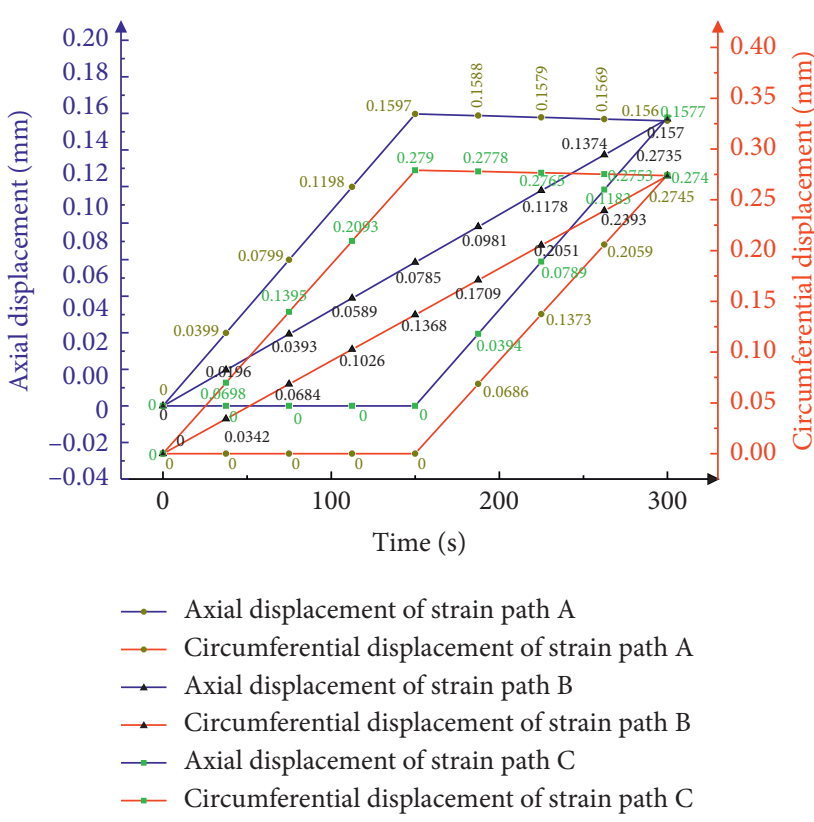

Figure 12: Three different strain path loading schemes.

requirement with high calculation efficiency (the aspect ratio of the mesh element was closed to 1 , that is, the element is close to a regular hexahedron).

3.1.3. FEA Results of Stress Path. The stress path loading was simulated using ANSYS 19.2 based on stress paths A, B, and $\mathrm{C}$ (shown in Figure 11). The average values of $\sigma_{z}(\mathrm{SZ})$ and $\tau_{\theta z}$ (SYZ) of Selection 1 were calculated based on the cylindrical coordinate system, the stress paths of which are shown in Figures 13(a)-13(c). The stress paths of $\sigma_{z}$ and $\tau_{\theta z}$ obtained according to the loading scheme shown in Figure 11 meet 
TABle 1: FEA results of stress paths $\mathrm{A}, \mathrm{B}$, and C.

\begin{tabular}{|c|c|c|c|c|c|c|c|c|c|c|c|c|}
\hline \multirow{3}{*}{ Path } & \multicolumn{12}{|c|}{ Strain } \\
\hline & \multicolumn{2}{|c|}{$\varepsilon_{z}^{e}\left(\times 10^{-3}\right)$} & \multicolumn{2}{|c|}{$\varepsilon_{z}^{p}\left(\times 10^{-2}\right)$} & \multicolumn{2}{|c|}{$\varepsilon_{z}\left(\times 10^{-2}\right)$} & \multicolumn{2}{|c|}{$\gamma_{\theta z}^{e}\left(\times 10^{-3}\right)$} & \multicolumn{2}{|c|}{$\gamma_{\theta z}^{p}\left(\times 10^{-1}\right)$} & \multicolumn{2}{|c|}{$\gamma_{\theta z}\left(\times 10^{-1}\right)$} \\
\hline & $\mu=0.5$ & $\mu=0.3$ & $\mu=0.5$ & $\mu=0.3$ & $\mu=0.5$ & $\mu=0.3$ & $\mu=0.5$ & $\mu=0.3$ & $\mu=0.5$ & $\mu=0.3$ & $\mu=0.5$ & $\mu=0.3$ \\
\hline Stress path A & 1.6840 & 1.6852 & 7.2659 & 7.2614 & 7.4343 & 7.4300 & 2.9197 & 2.5279 & 0.9044 & 0.9006 & 0.9336 & 0.9259 \\
\hline Stress path B & 1.6848 & 1.6831 & 6.4043 & 6.3725 & 6.5728 & 6.5409 & 2.9172 & 2.5280 & 1.2393 & 1.2394 & 1.2685 & 1.2646 \\
\hline Stress path C & 1.6876 & 1.6857 & 4.9065 & 4.8930 & 5.0753 & 5.0615 & 2.8588 & 2.4775 & 1.3702 & 1.3644 & 1.3987 & 1.3891 \\
\hline
\end{tabular}

TABLE 2: FEA results of strain paths A, B, and C.

\begin{tabular}{lcccr}
\hline \multicolumn{4}{c}{$\sigma_{z}(\mathrm{MPa})$} & \multicolumn{2}{c}{$\tau_{\theta z}(\mathrm{MPa})$} \\
Path & $\mu=0.5$ & $\mu=0.3$ & $\mu=0.5$ & $\mu=0.3$ \\
\hline Strain path $A$ & 230.69 & 212.91 & 153.82 & 162.22 \\
Strain path $B$ & 250.47 & 239.55 & 143.51 & 149.72 \\
Strain path $C$ & 271.41 & 273.29 & 130.94 & 129.91 \\
\hline
\end{tabular}

the requirement of Figure 8(a). The average values of $\varepsilon_{z}^{e}$ (EPELZ), $\varepsilon_{z}^{p}$ (EPPLZ), $\varepsilon_{z}$ (EPTOZ), $\gamma_{\theta z}^{e}$ (EPELYZ), $\gamma_{\theta z}^{p^{z}}$ (EPPLYZ), and $\gamma_{\theta z}$ (EPTOYZ) of Selection 1 were calculated, as shown in Table 1. The calculation results in Table 1 were based on $\mu=0.5$ [21], while the true Poisson's ratio of 304 stainless steel is about 0.3 . Therefore, the loading values were adjusted according to the above stress path analysis process, and the strain results corresponding to Poisson's ratio of 0.3 were added to Table 1 .

3.1.4. FEA Results of Strain Path. ANSYS 19.2 was used to simulate the effects of different strain loading paths of A, B, and $\mathrm{C}$, and the loading values were shown in Figure 12. The average values of $\varepsilon_{z}$ (EPTOZ) and $\gamma_{\theta z}$ (EPTOYZ) of Selection 1 were calculated based on the cylindrical coordinate system, and strain paths were shown in Figures 14(a)-14(c). The strain paths of $\varepsilon_{z}$ and $\gamma_{\theta z}$ obtained according to loading schemes, which are shown in Figure 13, meet the requirement of Figure $8(\mathrm{~b})$. The average values of $\sigma_{z}(\mathrm{SZ})$ and $\tau_{\theta z}$ (SYZ) of Selection 1 were calculated, as summarized in Table 2. The calculation results given in Table 2 were obtained for $\mu=0.5$ [22], while the true Poisson's ratio of 304 stainless steel is about 0.3 . Therefore, the loading values were adjusted according to the above strain path analysis process, and the stress results corresponding to Poisson's ratio of 0.3 were added to Table 2 .

\subsection{Experimental Results}

\subsubsection{Procedure}

(1) Specimen installation

The MTS809 tensile-torsional combined material test system was used for testing. This machine had a large loading speed range, force measurement range, and high accuracy and sensitivity for the measurement and control of loading, deformation, and displacement. The main technical parameters are axial force $( \pm 250 \mathrm{kN})$, torque $( \pm 2200 \mathrm{~N} \mathrm{~m})$, axial dynamic $(152.4 \mathrm{~mm})$, and steering dynamic $\left( \pm 45^{\circ}\right)$.
The specimens were divided into three groups, with 3 valid specimens in each group. The specimens were labeled as Stress Path A/B/C-1/2/3.

(2) Loading duration

The axial loading time of stress path A was $150 \mathrm{~s}$, followed by a torsional loading time of $150 \mathrm{~s}$. It took $300 \mathrm{~s}$ for simultaneous axial and torsional loading for stress path $B$. The torsional loading time of stress path $C$ was $150 \mathrm{~s}$, followed by an axial loading time of $150 \mathrm{~s}$.

(3) Tensile and torsional loading

According to the stress path loadings shown in Figure 11, the specimen was subjected to a tensiletorsional test and mechanical outputs such as displacement, rotation angle, tension, and torque were collected. The pictures of the specimens after the three stress paths being loaded are shown in Figure 15.

(4) Analysis and processing

Raw data were extracted, and Origin data processing software was used to analyze the test results.

3.2.2. Results of Stress Path Loading Tests. The stress-time curves of stress paths A, B and C are shown in Figure 16(a), 16(b), and 16(c). It can be observed that the stress path meets the requirements of Figure 8(a). Therefore, the strain results under this loading path can be used to analyze the "primary effect" affected by the stress path. Figures 17(a) and 17(b) depict the curves of normal strain and shear strain of the stress paths A, B, and C over time. The strains at the end of the loading are summarized in Table 3.

In Figures 16 and 17, irregular "warpage" and "saltation" phenomena can be seen in the middle section of the stress/strain curve with time. This is due to the fact that the material begins to enter a yield state at this point. The device's sensor was too slow to give feedback on the sudden decrease in the material modulus due to the sudden decrease in the ability of the material to resist deformation (i.e., the plastic modulus is much smaller than the elastic modulus), and hence, the "warpage" and "saltation" phenomena occurred in the stress/strain curve.

3.3. Comparative Analysis of Theoretical, Finite Element Analysis, and Experimental Test Results. The theoretical calculation results under different stress/strain loading paths were obtained from the literature $[21,22]$ and are shown in Table 4. 


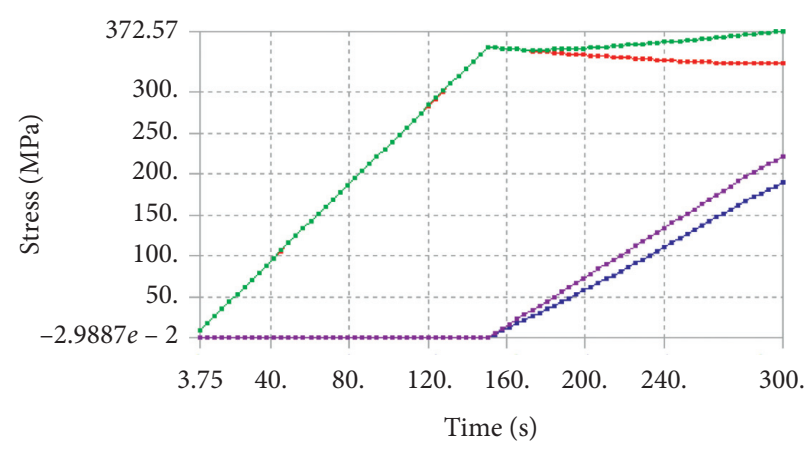

(a)

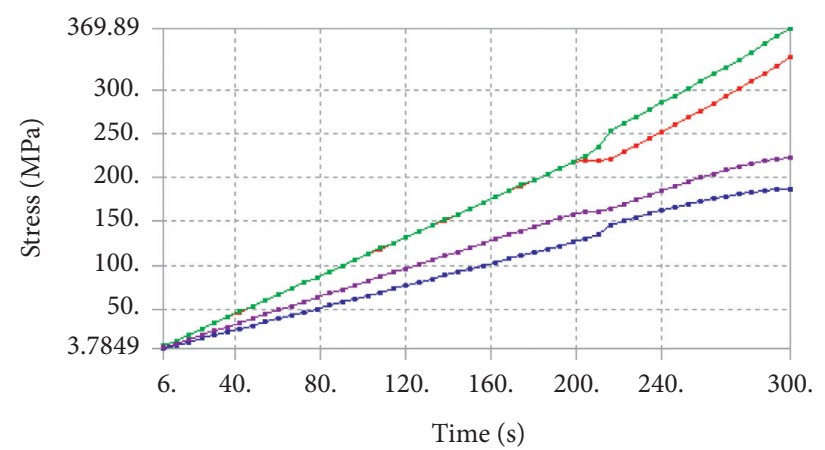

(b)

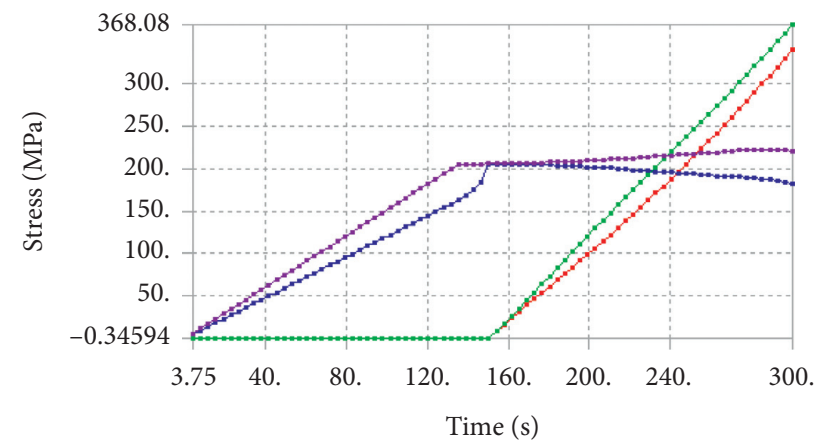

(c)

Figure 13: $\sigma_{z}$ and $\tau_{\theta z}$ of stress paths $\mathrm{A}(\mathrm{a}), \mathrm{B}(\mathrm{b})$, and $\mathrm{C}(\mathrm{c})$. Note. The green and red lines represent the maximum and minimum values of normal stress, respectively. The purple and blue lines represent the maximum and minimum values of shear stress, respectively.

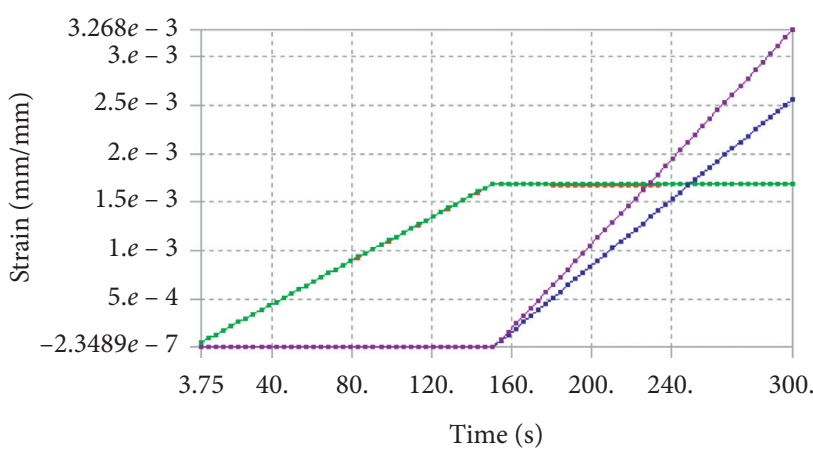

(a)

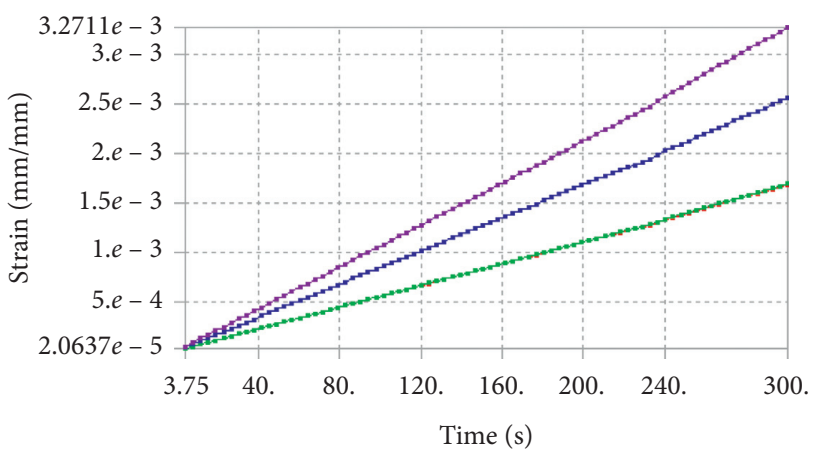

(b)

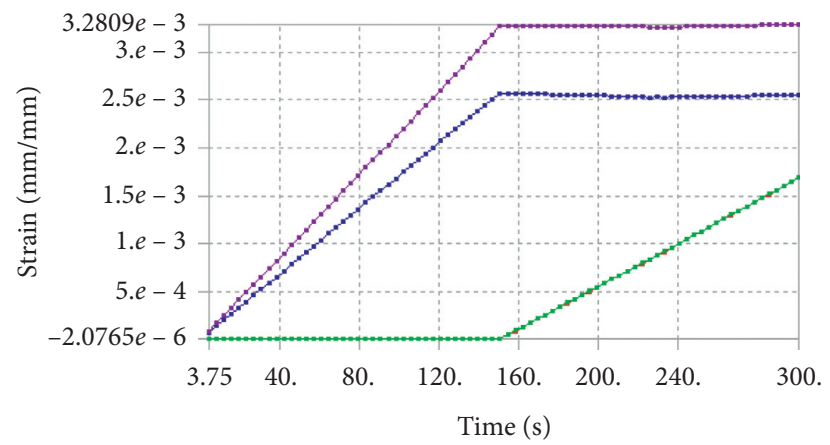

(c)

Figure 14: $\varepsilon_{z}$ and $\gamma_{\theta z}$ of strain paths A (a), B (b), and C (c). Note. The green and red lines represent the maximum and minimum values of normal stress, respectively. The purple and blue lines represent the maximum and minimum values of shear stress, respectively. 


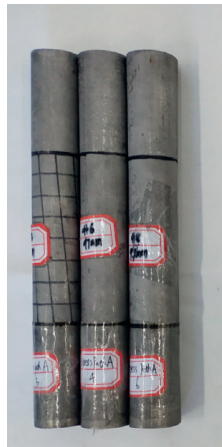

(a)

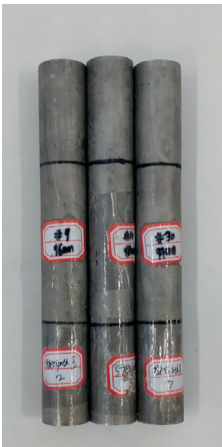

(b)

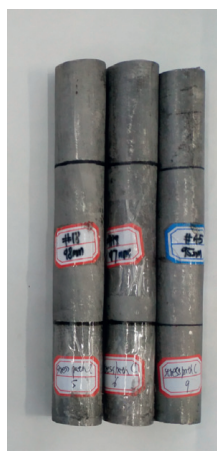

(c)

Figure 15: Pictures of specimens after loading stress paths (a) A, (b) B, and (c) C.

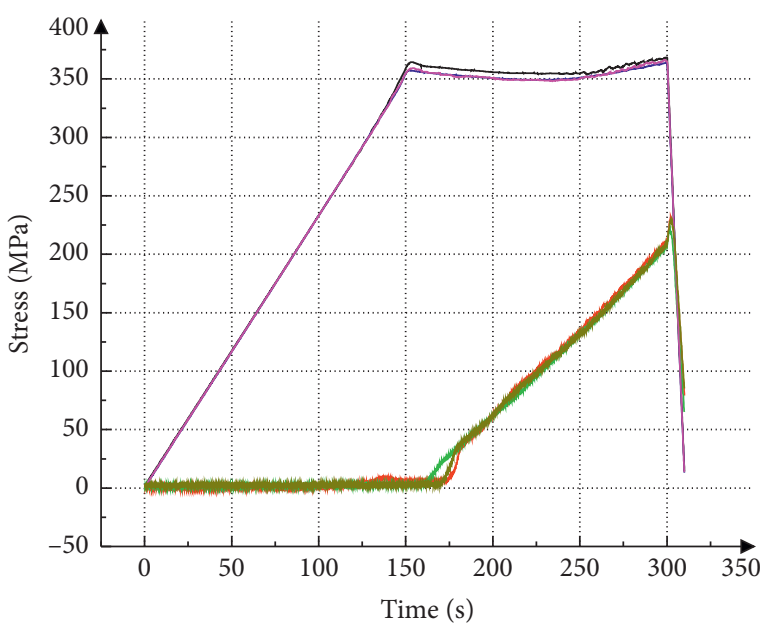

$\sigma_{z}$ of SPA-1

$-\tau_{\theta z}$ of SPA-1

- $\sigma_{z}$ of SPA-2 $\tau_{\theta z}$ of SPA-2

- $\sigma_{z}$ of SPA-3

- $\tau_{\theta z}$ of SPA-3

(a)

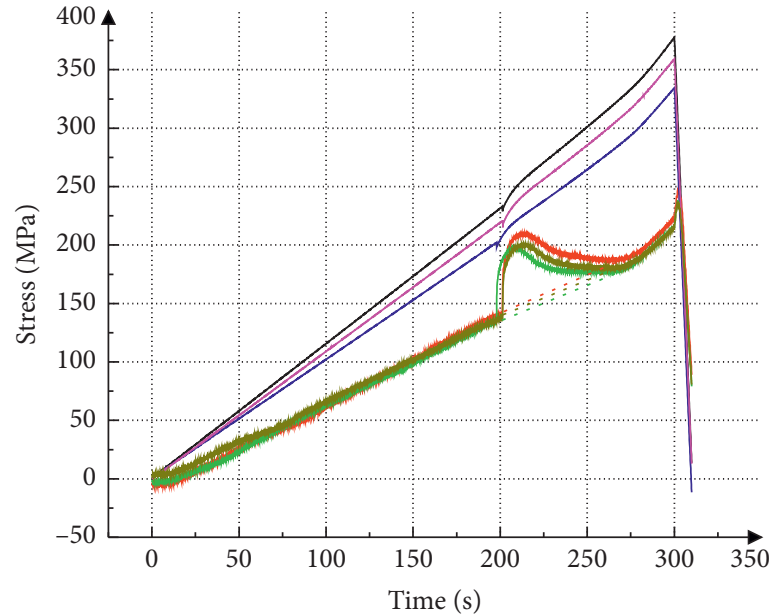

$-\sigma_{z}$ of SPB-1

$-\tau_{\theta z}$ of SPB-2

- $\tau_{\theta z}$ of SPB-1

- $\sigma_{z}$ of SPB-2

- $\sigma_{z}$ of SPB-3

$-\tau_{\theta z}$ of SPB-3
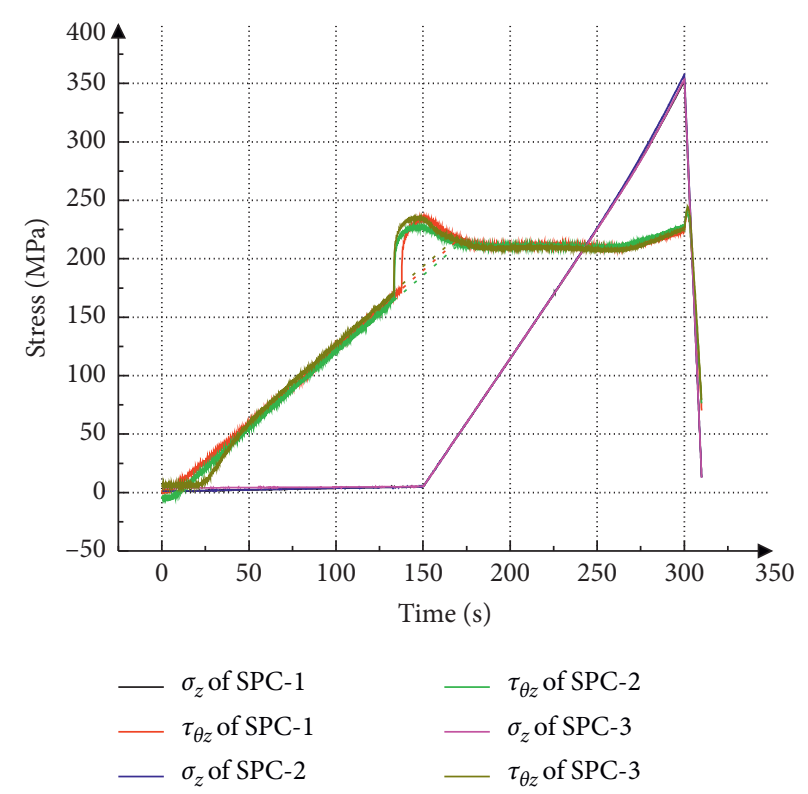

(c)

Figure 16: Stress-time curves of stress paths A (a), B (b), and C (c). 

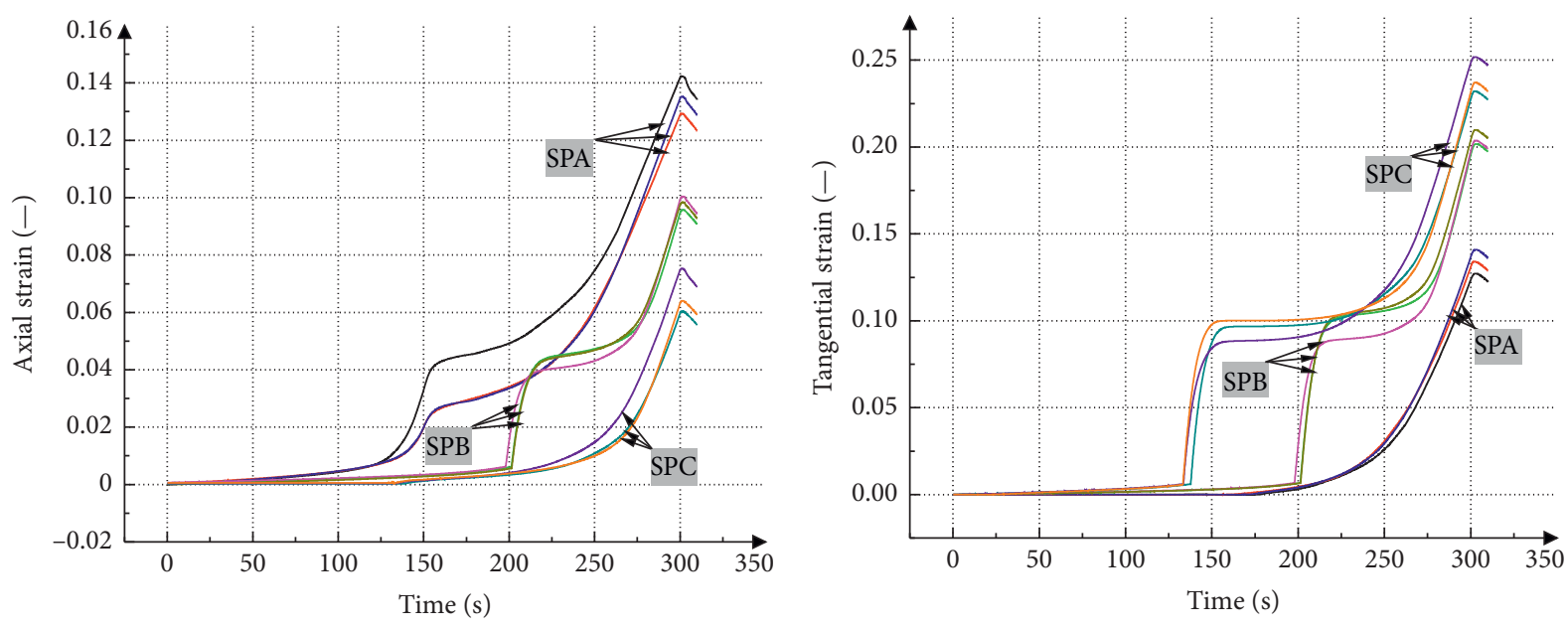

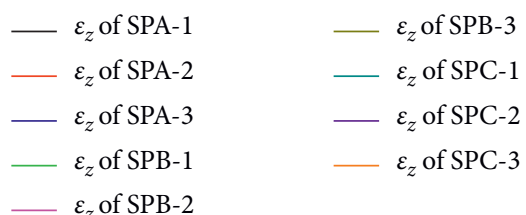

(a)

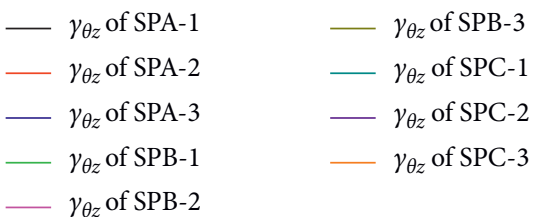

(b)

Figure 17: $\varepsilon_{z}$-time (a) and $\gamma_{\theta z}$-time (b) curves of stress paths $\mathrm{A}, \mathrm{B}$, and C.

TABLe 3: Strain results of stress paths A, B, and C.

\begin{tabular}{lcc}
\hline Path & $\varepsilon_{z}$ (mean) & Strain \\
\hline Stress path A & 0.1352 & $\gamma_{\theta z}$ (mean) \\
Stress path B & 0.0972 & 0.1306 \\
Stress path C & 0.0660 & 0.1991 \\
\hline
\end{tabular}

(1) $\varepsilon_{z}^{e}$ and $\gamma_{\theta z}^{e}$ in Table 1 were analyzed, and it was found that the elastic strain under different stress paths were partially consistent, which reflects the pathindependent effect of elastic strain.

(2) $\varepsilon_{z}^{p}$ and $\gamma_{\theta z}^{p}$ in Table 1 were analyzed, and it was found that the plastic strain values under different stress paths have a strict magnitude relationship, namely: $\varepsilon_{z}^{p A}>\varepsilon_{z}^{p B}>\varepsilon_{z}^{p C}$ and $\gamma_{\theta z}^{p A}<\gamma_{\theta z}^{p B}<\gamma_{\theta z}^{p C}$, thus verifying the results in the literature [23] that the stress path has a "primary effect" on the plastic strain.

(3) $\varepsilon_{z}$ and $\gamma_{\theta z}$ in Tables 1 and 3 were analyzed, and it was found that the total axial strain and the total tangential strain under different stress paths also have a strict relationship, namely: $\varepsilon_{z}^{A}>\varepsilon_{z}^{B}>\varepsilon_{z}^{C}$ and $\gamma_{\theta z}^{A}<\gamma_{\theta z}^{B}<\gamma_{\theta z}^{C}$. Combined with the "independentpath effect of elastic strain" in (1), the "primary effect" of the stress path on the plastic strain [23] is extended to the "primary effect" of the stress path on the total strain.

(4) $\sigma_{z}$ and $\tau_{\theta z}$ in Table 2 were analyzed, and it was found that the stress values under different strain paths have a strict relationship, namely: $\sigma_{z}^{A}<\sigma_{z}^{B}<\sigma_{z}^{C}$ and $\tau_{\theta z}^{A}>\tau_{\theta z}^{B}>\tau_{\theta z}^{C}$, thus verifying the results in the literature [23] that the strain path has a "recency effect" on the stress result.

(5) $\sigma_{z}$ (with relative differences of $0.8 \%, 0.3 \%$, and $0.9 \%$ ) and $\tau_{\theta z}$ (with relative differences of $0.9 \%, 0.4 \%$, and $0.9 \%$ ) in Tables 2 and 4 were comparatively analyzed when $\mu=0.5 . \varepsilon_{z}^{p}$ (with relative differences of $4.9 \%$, $8.8 \%$, and $12.8 \%$ ) and $\gamma_{\theta z}^{p}$ (with relative differences of $18.0 \%, 18.4 \%$, and $12.6 \%)$ in Tables 1 and 4 were comparatively analyzed when $\mu=0.5$. It can be seen that the relative difference was small, indicating that the theoretical calculation results matched with the finite element analysis results.

$\varepsilon_{z}$ (with relative differences of $45.0 \%, 32.7 \%$, and $23.3 \%$ ) and $\gamma_{\theta z}$ (with relative differences of $29.1 \%$, $36.5 \%$, and $41.1 \%$ ) in Tables 1 and 3 were comparatively analyzed when $\mu=0.3$. It can be seen that the relative difference was relatively large, which indicates that a big gap existed between the experimental results and the finite element analysis results. This is because the plastic modulus and section stiffness of the material showed a rapid attenuation state after entering the plastic stage, which led to a sharp decline in the ability to resist deformation, resulting in a large amount of deformation. On the contrary, the material was modeled having linear strengthening (the plastic modulus is a fixed value) in the finite element model, and hence, the amount of deformation was small.

(6) The changes in strain for different values of Poisson's ratio in Table 1 were analyzed, and it was found that the change of Poisson's ratio value had no effect on 
TABLE 4: The theoretical calculation results under different stress/strain loading paths.

\begin{tabular}{|c|c|c|c|c|c|c|c|c|c|}
\hline \multirow{3}{*}{$\begin{array}{l}\text { Path } \\
\text { Stress path A }\end{array}$} & \multicolumn{4}{|c|}{ Strain } & \multirow{3}{*}{$\begin{array}{c}\text { Path } \\
\text { Strain path A }\end{array}$} & \multicolumn{4}{|c|}{ Stress } \\
\hline & \multicolumn{2}{|l|}{$\begin{array}{c}\varepsilon_{z}^{p}\left(\mathrm{x} 10^{-2}\right) \\
\mu=0.5\end{array}$} & \multicolumn{2}{|l|}{$\begin{array}{c}\gamma_{\theta z}^{p}\left(\mathrm{x} 10^{-1}\right) \\
\mu=0.5\end{array}$} & & \multicolumn{2}{|c|}{$\begin{array}{c}\sigma_{z}(\mathrm{MPa}) \\
\mu=0.5\end{array}$} & \multicolumn{2}{|c|}{$\begin{array}{c}\tau_{\theta z}(\mathrm{MPa}) \\
\mu=0.5\end{array}$} \\
\hline & $\left(\sigma_{s} / h\right)(\ln 2 / 2)$ & 6.9119 & $\left(\sigma_{s} / h\right)(\sqrt{3}(1-\pi / 4))$ & 0.7413 & & $\sigma_{s} / \operatorname{ch} 1$ & 228.76 & $\left(\sigma_{s}\right) /(\sqrt{3}$ th 1$)$ & 155.22 \\
\hline Stress path B & $\left(\sigma_{s} / h\right)(1-1 / \sqrt{2})$ & 5.8413 & $\left(\sigma_{s} / h\right)(\sqrt{3}(1-1 / \sqrt{2}))$ & 1.0117 & Strain path B & $\sigma_{s} / \sqrt{2}$ & 249.61 & $\sigma_{s} / \sqrt{6}$ & 144.11 \\
\hline Stress path C & $\left(\sigma_{s} / h\right)(1-\pi / 4)$ & 4.2799 & $\left(\sigma_{s} / h\right)(\sqrt{3} \ln 2 / 2)$ & 1.1972 & Strain path $\mathrm{C}$ & $\sigma_{s}$ th 1 & 268.84 & $\left(\sigma_{s}\right) /(\sqrt{3 \operatorname{ch} 1})$ & 132.08 \\
\hline
\end{tabular}

the axial strain $\left(\varepsilon_{z}^{e}, \varepsilon_{z}^{p}, \varepsilon_{z}\right)$ and the plastic part of the shear strain $\left(\gamma_{\theta z}^{p}\right)$ and had the greatest impact on the elastic part of the shear strain $\left(\gamma_{\theta z}^{e}\right)$. This is because the change in Poisson's ratio mainly affects the shear modulus of the material. Poisson's ratio of the material in the elastic stage is constant, so different shear modulus $G(G=E /[2(1+\mu)])$ values are obtained at different $\mu$ values, which affects the elastic part of the shear strain $\left(\gamma_{\theta z}^{e}\right)$. Poisson's ratio of the material increases and tends to the limit value of 0.5 during the plastic deformation process when the material enters the plastic stage $[25,26]$. Therefore, Poisson's ratio of the steel had little effect on the plastic part of the shear strain $\left(\gamma_{\theta z}^{p}\right)$, even when it was given different initial values in the ANSYS material database.

\section{Discussion}

4.1. Primary Effect and Recency Effect. For the same stress/ strain endpoint, analytical solutions under different stress/ strain paths were obtained by the theoretical derivation of two classical cases [21,22]. The results demonstrated that the stress/strain path affected the final states of strain/stress of the material. However, these two textbooks stop at the basic judgment of "different." As for how it is different, why it is different, whether there is a certain rule in the difference, etc., there is no answer.

Based on rigorous mathematical derivation and discussion in previous studies [23], Gao et al. proposed the "primary effect" of the stress path and the "recency effect" of the strain path and compared the discovered laws with the classical theories in social psychology. Besides, they also demonstrated the universality, relevance, and unity of "primary effect" and "recency effect" in the entire stress/ strain domain.

The same result can be obtained by using finite element analysis software to adjust the endpoint of the stress/strain path to any point in the plastic stress/strain domain, that is, the preloaded stress dominates the final plastic strain under different stress paths, while the postloaded strain dominates the final stress result under different strain paths. Based on the classical case [21], experimental analysis was conducted on the stress path loading, which provided the test basis for the "primary effect" of the stress path. During the "recency effect" test, the displacement loading of the standard specimen was $0.16 \mathrm{~mm}$ in axial extension, and $1^{\circ}$ in circumferential torsion angle, respectively. Due to the small deformation, the deformation reached the same level as the displacement of the testing machine system. Hence, the error caused by the displacement of the testing machine seriously affected the control of the true displacement of the specimen, resulting in unsatisfactory test results of "recency effect". The accuracy of displacement control about "recency effect" is the next research direction that needs improvement and efforts.

The "primary effect" of stress path and "recency effect" of strain path are inevitable results of the plastic strengthening of materials from the perspective of physical mechanism. Rigorous derivation at the theoretical level [23], finite element simulation, and the test of a representative case are found to be sufficient to show that the "primary effect" and "recency effect" are not based on the individual laws of specific cases but are valid for the entire plastic stress/strain domain and have a relatively strong universality.

4.2. Applications and Inspirations. Elastoplastic mechanics has a high degree of abstraction and complexity. It is recognized as a hard-to-teach and hard-to-learn course for teachers and students in the professional basic courses of colleges and universities. The derivation process is mostly obscure, and the core concepts are intertwined, especially in plastic mechanics. Hence, higher requirements are put forward for teachers in terms of teaching methods [27-30]. Based on the problem of the tensile-torsional loading path effect of thin-walled circular tubes, finite element method and experimental verification of the two effects of loading path are carried out, and the effect of loading path on the final stress and strain states of the material after entering plastic deformation stage is visualized. Adhering to the teaching philosophy of "taking one step more and going deeper" [31], we make the principles of the two effects more deeply rooted in the hearts of people, help students to establish an effective knowledge framework, and deepen the understanding of the effects of plastic deformation. The indepth analysis of the two effects is of great benefit for teachers teaching the relevant chapters of plastic mechanics, provides guidance for students to quickly judge and solve problems, adds vitality to classroom, and achieves good teaching effects.

Combination of tension and torsion deformations is rather common in engineering. The shaft connected to the propeller on a helicopter and the drill tube in an oil drilling project are all subjected to combined tensile and torsional loads. The specimen in this paper was a 304 stainless steel thin-walled tube, which is a rather common engineering material. 304 stainless steel is widely used in nuclear power plant tubes, household goods, auto parts, medical appliances, and ship parts because of its high toughness, easy 
processing, good welding performance, and strong corrosion resistance [32]. Through a series of tensile and torsion tests, it was verified that the material was highly consistent with the classical elastoplastic mechanics theories. This indicates that the laws of "primary effect" and "recency effect" established based on classical elastoplastic mechanics theories such as the von Mises yield criterion and assumption of isotropic linear hardening are not idealized individual theories but universal laws with good application prospects that can be extended to actual engineering materials. However, further research is needed on whether this law can be extended to more general situations, such as nonlinear follow-up hardening materials, complex loading paths, and complex working conditions that bear tensile, bending, and torsion loads.

\section{Conclusions}

Based on classical elastoplastic mechanics theory, finite element analysis and experimental verification of the effect of loading path in the tension and torsion problems of thinwalled circular tubes were carried out in this study. The similarities and differences of the results obtained from theoretical calculations, finite element analyses, and experimental tests were analyzed. In addition, the application of the two universal laws was investigated. The following main conclusions were made:

(1) For the same endpoint of stress, strain results showed the following relationships for different stress paths (A: tension followed by torsion, B: proportional loading, and $\mathrm{C}$ : torsion followed by tension): $\varepsilon_{z}^{A}>\varepsilon_{z}^{B}>\varepsilon_{z}^{C}, \gamma_{\theta z}^{A}<\gamma_{\theta z}^{B}<\gamma_{\theta z}^{C}$. This showed that the effect of stress paths on strain results was consistent with the "primary effect."

(2) For the same endpoint of strain, stress results showed the following relationships for different strain paths (A: tension followed by torsion, B: proportional loading, and $\mathrm{C}$ : torsion followed by tension): $\sigma_{z}^{A}<\sigma_{z}^{B}<\sigma_{z}^{C}, \tau_{\theta z}^{A}>\tau_{\theta z}^{B}>\tau_{\theta z}^{C}$. This showed that the effect of strain paths on stress results conformed to the "recency effect."

(3) In this paper, two common concepts of psychology were used to vividly summarize the complex mathematical derivation and profound mechanics principles. It not only stimulates the attention of students in teaching process but also helps students understand the loading path effect in plastic mechanics, which has a good effect on teaching.

\section{Abbreviations}

$D_{0}$ : $\quad$ Original external diameter of the tube $(\mathrm{mm})$

$d_{0}$ : Original internal diameter of the tube $(\mathrm{mm})$

$S_{0}$ : $\quad$ Original cross-sectional area $\left(\mathrm{mm}^{2}\right)$

$L_{0}$ : $\quad$ Original gauge length $(\mathrm{mm})$

$L_{c}: \quad$ Parallel length $(\mathrm{mm})$

$L_{h}: \quad$ Clamping length $(\mathrm{mm})$

$L_{t}$ : Total length of the specimen ( $\mathrm{mm}$ )
$L_{b}: \quad$ Length of the plug head ( $\mathrm{mm}$ )

E: $\quad$ Elastic modulus (GPa)

$G$ : $\quad$ Shear modulus $(\mathrm{GPa})$

$h$ : Plastic modulus (GPa)

$\sigma_{s}: \quad$ Yield stress $(\mathrm{MPa})$

$\sigma_{u}: \quad$ Ultimate tensile stress ( $\left.\mathrm{MPa}\right)$

$\sigma_{z}: \quad$ Normal stress $(\mathrm{MPa})$

$\tau_{\theta z}: \quad$ Shear stress $(\mathrm{MPa})$

$\varepsilon_{z}: \quad$ Axial strain (-)

$\varepsilon_{z}^{e}: \quad \quad$ Axial elastic strain (-)

$\varepsilon_{z}^{p}: \quad$ Axial plastic strain $(-)$

$\gamma_{\theta z}: \quad$ Tangential strain (-)

$\gamma_{\theta z}^{e}: \quad$ Tangential elastic strain $(-)$

$\gamma_{\theta z}^{p}: \quad$ Tangential plastic strain $(-)$

$N: \quad$ Axial tensile force $(\mathrm{N})$

$T: \quad$ Circumferential torque $(\mathrm{N} \cdot \mathrm{mm})$

$\mu$ : $\quad$ Poisson's ratio $(-)$

SPA/B/C: Stress path A/B/C

FEA: $\quad$ Finite element analysis.

\section{Data Availability}

The data used to support the findings of this study are included within the article.

\section{Conflicts of Interest}

The authors declare that they have no conflicts of interest related to this work.

\section{Acknowledgments}

The authors would like to express our gratitude to Weiguo Wu, Hongguang Liu, Shiping Jiang, Rui Hang, and Jingyi Shao from Jiangsu University for their suggestions and assistances to the test. The authors would like to acknowledge the Postdoctoral Research Fund for the financial support for this study (no. 2018M643852).

\section{Supplementary Materials}

With the development of oil drilling technology, land and deep-sea oil and gas resources have successively entered the exploration and development stage, which also puts forward higher requirements for the strength of drill pipes [33, 34]. At present, the highest strength of the API series drill pipe is the S135 grade drill pipe, but as the drilling depth increases, it can no longer meet the drilling requirements of some ultra-deep wells. In addition to producing and supplying in accordance with API Spec 5D, domestic and foreign oil well drill pipe manufacturers have also developed high-performance non-API grade drill pipes to meet the special needs of users. Therefore, drilling tool manufacturers have successively developed V-150 high-strength drill pipes, which have been widely used [35]. Compared with API S135 drill pipes, the strength of V-150 high-strength drill pipes can be increased by at least $103 \mathrm{MPa}$, which not only increases the drilling depth but also increases the water hole size appropriately, which can increase drilling discharge, reduce 
circulating pressure consumption, and increase drilling efficiency by more than $50 \%$. This is of great significance for ultra-deep well drilling and ocean exploration [36, 37]. (Supplementary Materials)

\section{References}

[1] Z. Shu, Z. Ouyang, and P. Yuan, "The mechanical performance of V150 drill tube under combined tension-torsion loading," Petroleum Drilling Techniques, vol. 47, pp. 68-73, 2019.

[2] T. Aida, T. Aso, and Y. Imada, "Combination resonance of thin-walled structural members subjected to periodic axial follower torque and force," Journal of Sound and Vibration, vol. 183, no. 4, pp. 693-706, 1995.

[3] J. Wang, H. Wang, W. Lv, and D. Liu, "Fatigue characteristics and life prediction of thin-wall circular tube with holes under combined tension-torsion loading," in Proceedings of 2014 Cross Strait Symposium on Damage Science and Material Testing and the 12th Symposium on Damage Science/the 10th National MTS Material Test Conference 2014, pp. 24-25, Nantou, China, October 2014.

[4] V. Chaves, G. Beretta, and A. Navarro, "Biaxial fatigue limits and crack directions for stainless steel specimens with circular holes," Engineering Fracture Mechanics, vol. 174, pp. 139-154, 2017.

[5] M. Bodaghi, A. R. Damanpack, M. M. Aghdam, and M. Shakeri, "A phenomenological SMA model for combined axial-torsional proportional/non-proportional loading conditions," Materials Science and Engineering: A, vol. 587, pp. 12-26, 2013.

[6] G. Hu, K. Zhang, Y. Shi, and L. Su, "Crystal plasticity numerical analysis on yield and subsequent yield of polycrystalline copper under combined tension--torsion loading," Acta Metallurgica Sinica, vol. 46, no. 4, pp. 466-472, 2010.

[7] W. Zhang, Y. Liu, F. Lu, and Y. Sun, "A tensional-torsional strain measuring method for thin-walled tubular specimens based on digital image," China Measurement and Testing Technology, vol. 42, pp. 20-23, 2016.

[8] C. Guo, P. Li, X. Jiang, Z. Hu, and L. Sun, "Plastic collapse load analysis of circumferentially cracked tubes under combined loads of axial force, bending moment, torsion and internal pressure," Pressure Vessel Technology, no. 2, pp. 3-9, 1999.

[9] W. Wang, P. Jiang, J. Zhang, Y. Liu, and H. Chen, "Numerical analysis of the influences of torsional load amplitude on the stress of components under non-proportional combined tension-torsion cyclic loading," in Proceedings of the 2010 Symposium of the Turbine Committee of Chinese Society of Power Engineering, Shanghai, China, October 2010.

[10] Z. Zhang, I. S. Cinoglu, A. Charbal, N. Vermaak, L. Lou, and J. Zhang, "Cyclic inelastic behavior and shakedown response of a 2nd generation nickel-base single crystal superalloy under tension-torsion loadings: experiments and simulations," $E u$ ropean Journal of Mechanics - A/Solids, vol. 80, Article ID 103895, 2020.

[11] A. E. Antoniou, C. Kensche, and T. P. Philippidis, "Mechanical behavior of glass/epoxy tubes under combined static loading. Part II: validation of FEA progressive damage model," Composites Science and Technology, vol. 69, no. 13, pp. 2248-2255, 2009.

[12] D. Shang, W. Yao, and D. Wang, "Study on cyclic stress-strain relation under tension-torsion complex loading," Chinese Journal of Applied Mechanics, vol. 3, pp. 66-70, 1999.
[13] D. Floros, A. Ekberg, and K. Runesson, "A numerical investigation of elastoplastic deformation of cracks in tubular specimens subjected to combined torsional and axial loading," International Journal of Fatigue, vol. 91, pp. 171-182, 2016.

[14] A. Fatemi, N. Gates, D. F. Socie, and N. Phan, "Fatigue crack growth behaviour of tubular aluminium specimens with a circular hole under axial and torsion loadings," Engineering Fracture Mechanics, vol. 123, pp. 137-147, 2014.

[15] V. Chaves, G. Beretta, J. A. Balbín, and A. Navarro, "Fatigue life and crack growth direction in 7075-T6 aluminium alloy specimens with a circular hole under biaxial loading," International Journal of Fatigue, vol. 125, pp. 222-236, 2019.

[16] P. Zhu, P. Feng, Q.-P. Sun, J. Wang, and H.-H. Dai, "Determining the up-down-up response through tension tests of a pre-twisted shape memory alloy tube," International Journal of Plasticity, vol. 85, pp. 52-76, 2016.

[17] K. Enakoutsa, "Combined stretching and twisting of a circular thin-walled tube of second gradient plastic material," International Journal of Engineering Science, vol. 78, pp. 114-123, 2014.

[18] J. Wu, "Experimental study on strain path control of thinwalled tube in tension and torsion, Chinese Society of Mechanical Engineering," in Proceedings of the 8th National Symposium on Plastic Processing, Beijing, China, November 2002.

[19] B. Wang, K. Zhang, and Z. Tang, "An experimental study on the stress waves with phase transition under combined tension-torsion loading," Journal of Vibration and Shock, vol. 36, pp. 29-33, 2017.

[20] X. Wang, G. Lu, and Y. J. Lu, "Buckling of embedded multiwalled carbon nanotubes under combined torsion and axial loading," International Journal of Solids and Structures, vol. 44, no. 1, pp. 336-351, 2007.

[21] M. Chen, Elastoplastic Mechanics, pp. 271-273, Science Press, Beijing, China, 2007.

[22] B. Xu and X. Liu, Applied Elastoplastic Mechanics, pp. $103-$ 107, Tsinghua University Press, Beijing, China, 1995.

[23] Y. Gao, F. Shao, P.-X. Fan, Q. Xu, J. Gu, and S.-L. Wang, "Primary and recency effects based on loading path in classical plasticity," Journal of Central South University, vol. 27, no. 9, pp. 2592-2605, 2020.

[24] ISO, Metallic Materials-Tensile Testing, Part 1, Method of Test at Room Temperature ISO6892-1: 2009, ISO, Geneva, Switzerland.

[25] B. Xu and S. Chen, A Concise Course of Plastic Theory, Tsinghua University Press, Beijing, China, 1981.

[26] J. Feng, Z. Lian, and Y. Sun, "The effect of Poisson ratio of material properties on plastic yield," Journal of Daqing Petroleum Institute, vol. 3, pp. 74-76, 2003.

[27] H. Liu and J. Lv, "Discussion on structural system and teaching method of elastoplastic mechanics," Chinese Geological Education, vol. 26, pp. 32-35, 2017.

[28] H. Wang, L. Xie, H. Zhou, L. Li, and J. Zhu, "Discussion and practice of interactive and visual teaching method of elastoplastic mechanics," Mechanics in Engineering, vol. 40, pp. 687-692, 2018.

[29] H. Zhou, "The past and present of mechanics education," Mechanics in Engineering, vol. 37, pp. 113-116, 2015.

[30] B. Xu and X. Wang, "Discussion on the simplification of elastoplastic mechanics," Mechanics in Engineering, vol. 37, pp. 395-396, 2015.

[31] Z. Xu, "How to improve the quality of classroom teaching," People's Education, vol. 10, pp. 27-29, 1979. 
[32] X. Tong, W. Gu, S. Zhu, and T. Bai, "Measurement and elimination of surface residual tensile stress of 304 stainless steel thin-wall welded tube," Materials for Mechanical Engineering, vol. 36, pp. 80-82, 2012.

[33] H. Li, W. Tian, and X. Kuang, "OCTG supply-demand situation and countermeasures," Steel Pipe, vol. 39, no. 1, pp. 1-7, 2010.

[34] M. J. Jellison, R. B. Chandler, M. Payne, and J. S. Shepard, "Ultradeep drilling pushes drillstring technology innovations," SPE Drilling \& Completion, vol. 23, no. 2, pp. 190-200, 2008.

[35] D. Gong, S. Yu, P. Yuan, and Y. Shuai, "Fracture failure analysis of V150 high-strength drill pipe," Heat Treatment of Metals, vol. 40, no. 10, pp. 205-210, 2015.

[36] Y. Li, H. Li, X. Wang et al., "Effect of tempering process on strength and toughness of oil casing tube for ultra-deep well," Journal of Central South University (Science and Technology), vol. 44, no. 6, pp. 2244-2251, 2013.

[37] R. Yu and P. Yuan, "Aluminum drill pipe characteristics and potential applications," Oil Field Equipment, vol. 40, no. 3, pp. 81-85, 2011. 